\title{
REVIEW OF SOME STUDIES OF RACHITIC SKULLS OF MONKEYS.
}

By F. HECKER, B.S., D.D.S., A.M., M.D.

Direclor of Research Laboratory of the Dewey School of Orthodontia, Kansas City, Mo.

$\mathbf{I}^{\mathrm{T}}$ has long been known that many of the lower animals at variable periods after their captivity develop a softening of the osseous skeleton.

Otto, in 1814, described a softening of the bones of the skull in young dogs. Curlt, in 1838 , described a similar condition present in the bones of the skulls of monkeys in captivity. The investigations of the foregoing observers were substantiated by Crisp and Marie. Percey, in 1844, reported a brown cebus which, after having been placed in captivity, developed the disease to such an extent that a general deformity resulted. As the disease progressed, various bones of the body broke spontaneously, the most pronounced fracture being of the hind legs. At this stage in the development of the disease, the animal lost all control of the broken legs, and when it moved about the cage the legs were dragged after it. At an autopsy, a careful examination of the viscera was made, and no pathological changes were noted.

Vrolik, in 1848 , observed a marked thickening in a macacus nemistrimus.

Up to 1844 , the condition which we now know and recognize as rickets, was not considered as rickets by the early writers, but instead, they called it hyperostosis, osteomalacia, scorbutus, etc. Huschke was the first author to associate the bony changes noted in the skulls of monkeys with rickets. His studies were carried on in the museum at Jena. One skull which especially attracted his attention was that of a young pavian, which, when measured, showed in comparison to other skulls of the same species, an incrcase of $14 \mathrm{~mm}$. in its size. The fontanels of this animal's skull were all open, the lamina interna was partially divided. After the publication of Huschke's observations, the softening of the bones noted in monkeys was known as rickets. Schmidt, a former director of the Zoological Gardens of Berlin, was an excellent student and observer of the diseases of monkeys, and in his studies he reported a brown pavian whose legs showed a marked rachitic bending, and staces that a similar process was present in a cercopithecus and also in a cebus capucinus. Schmidt did not consider the condition observed as a rachitic one, but as an osteomalacia. In 1889, Hutchinson and Sutton observed that monkeys in captivity developed deformities of their legs and heads. Hutchinson published his observations under the title of "Ostitis Deformens", while Sutton published his under the title of "Leontiasis Ossea". At a later date, Sutton published his second paper, in which he considers the malady as rickets, and he further states that the majority of the apes in the London Zoological Gardens die of this malady.

Von Hanseman, through the courtesy of Heck, Director of the Zoological Gardens of Berlin, was able to make an extensive study of the monkeys in those gardens. His principal studies were confined to young monkeys who had not shed their first teeth, and who had been in the zoological gardens for one month or more. The first symptom of the onset of the disease was that the monkeys did not climb about in their cages as readily as they did 
when they were first placed in them, and further that they were more content to sit on the rests placed in the cages. This first symptom of the disease was soon followed by marked inactivity of the animal, and it seldom sprang from one place to another in the cage as it had done when first placed therein. This stage was followed by a more marked inactivity of the animal, and a little later the hind legs became affected, showing weakness to a slight degree at first, but as the disease progressed the weakness became more marked. The monkey no longer indulged in the caprices of its healthier fellows, but sat upon the floor of the cage. When the animal reached this stage in the development of the disease, it made no effort to stand on its hind legs when moving about, but instead slid about on the floor of the cage on its hind quarters. This stage was soon followed by complete loss of control of the hind legs, after which the front legs became affected, and they also became useless. The animal now became helpless and lay about on its belly in the cage. When the monkey became helpless, its fellows commenced to tease and torment until the animal, in sheer exhaustion, died. The most common complications which accompany the final stage of the disease are pneumonia. tuberculosis, and spontaneous fracture of the affected bones. In addition to the bending of the legs, the overgrowth of the bones of the skull causes a marked deformity of the face of the animal, the upper jaw becomes short and thick, and because of the excessive osseous development, the mouth of the affected animal is constantly open. In addition to the foregoing deformities, the back of a monkey affected by rickets assumes the contour of a mad cat. Careful examination of the animal after death shows that this latter deformity is not kyphosis.

An examination of the epiphysis of the affected bones shows them to be markedly swollen, and also that the ends of the ribs at the point of union with the cartilage of the sterum are also swollen. If it is the good fortune of the animal to recover from the disease, the bones again return to normal, and if by chance any of the bones are broken during the presence of the disease, they heal quite readily; but at the point at which the fracture occurs there is generally a deformity of the bone. Some of the animals which re. covered from the disease lived for fifteen years afterwards.

From the foregoing observation of Von Hanseman, we learn that Sutton was not entirely correct in his report that all of the monkeys in captivity. die of rickets. At the autopsy, the viscera of many of the dead monkeys presented a picture which greatly resembles tuberculosis, pneumonia, and follicular catarrh of the small intestine as in man, and also an enlargement of the spleen and nodulation of the stomach.

The periosteum of the bones of monkeys affected by rickets is softened, and, as a whole, is more markedly affected than in man. This, in many instances, is not confined to parts which show a deformity, but the entire periosteum of the bony skeleton is affected. The deformity of the head of an animal affected by this process shows more markedly than in any other part of the body, for here we observe a marked increase in the thickness of the bones, and they are very soft and porous with a marked sof tening of the periosteum covering them.

One of the monkeys which Von Hanseman studied had been privately owned for five years prior to its entrance to the Berlin Zoological Gardens. 
This animal did not make the effort to escape which monkeys generally do after they are placed in the cage. Further observation showed that the monkey was not as active as its fellows, that its movements werc sluggish, and that a considerable amount of prodding was required to make it move, once it became settled in a comfortable position. This sluggishness persisted for a short time, after which all of the symptoms of rickets commenced to manifest themselves. The snout of the animal became markedly thickened, the canine fossa was very pronounced, the central and lateral incisors showed a developing malocclusion, and the canines commenced to rotate mesially. At this stage of the disease the molars showed no change in their position, and the occlusion was normal. The long bones of the animal showed various deformities at the time of death.

Another skeleton studied by Von Hanseman was that of a cebus capucinus which had been in captivity fifteen years, three years of its captivity being spent in the Berlin Zoological Gardens. This animal, in contrast to the one just mentioned, did not show a deformity of the skull, but it did show a more marked deformity of the long bones. In addition to the deformities of the long bones, there was a marked shortening of the long bones of its fore-legs when compared to the normal length of the long bones of the same species. The spine of this animal was very markedly bent, resembling kyphosis. The upper arm on either side was markedly bent in its upper third, as were also the ulna and the radius. In addition to the bending, there was a marked thickening of the bones. Von Hanseman states that the spinal canal is also variably affected. Sutton, in his studies of the lining membrane of the spinal canal, learned that there is a variable softening of it, and he concludes that because of this process the functional nerves do not have a normal exit, and hence the animal develops a lameness which is dependent on the extent of the softening of the lining membrane. Van Hanseman does not agree with Sutton in this explanation of the lameness of the animal; on the other hand he contends that the process noted is a transverse myelitis. In all of the specimens examined Von Hanseman was unable to find a softening of the spinal canal.

We have seen from the foregoing that rickets exists in the monkey, and therefore can begin a further study of this disease and its effects on the bones of the skull, and then by analogy we can form mental impressions of this disease, when present in the human skull.

The lower jaw shows a variable separation with small points of osteophytic development. In some places the osteophytic process builds on the surface of another osteophytic process. Hence, by this process of overdevelopment, one can readily comprehend how the contour of the bone is changed. At some later period these osteophytic areas become completely calcified, and by this latter process is explained the marked thickening so of ten observed in the bones of the skull. The most rational explanation offered for this process is that the blood vessels are markedly dilated, and that at the same time there occurs a thickening of the periosteum; and further, a variable inflammation is presènt. The bone affected by this disease is very porous, and the fresh specimen has a blood-red color. A like color is observed in the bone in which the osteophytic process is present. The condition of the periosteum in man is, no doubt, the same as that observed in monkeys. 
The diploe in the monkeys present the same picture as observed in man, and the dura likewise is not affected.

In many instances one notes that there is very marked softening of the occipital region of the skull which on examination resembles a craniotabes. Elsasser contends that this softening of the bone is the result of pressure from the brain when the animal (or human) affected by rickets is lying upon its back, granting, of course, that the head is resting on its occipital portion. This may be the case in the child, but it is not likely that such is the case in monkeys.

In an examination of the skull of the simia satyrus, Von Hanseman observed that there was a marked thickening of the periosteum, and that when the periosteum was removed the greater portion of the skull was soft and porous, but that occasionally a small area of calcified bone was noted. A further examination of the skull of this animal showed that the teeth were very insecure in their position, and that the distal root of the third molar was completely denuded of alveolus, as were also the roots of the second molar. The alveolus in the interproximal spaces between the teeth also showed a marked absorption. Many of the skulls which Von Hanseman examined showed a compensatory osseots development in the course of the development of rickets.

The softening of the bones is periosteal in character, and it is supposed that when fractures occur, these softened areas are the places of fracture. When infections occur, they likewise occur in these areas. This observation is very unlike that observed in healthy individuals in the process of developing bone. The early investigators held that the development of rachitic bone shows it to be an outgrowth from the outer plate of the bone, and that coincident with this process there is an absorption of the inner plate of the bone. Von Hanseman, in his investigation of this theory, came to the conclusion that the foregoing explanation was not correct. He found that the inner plate is not destroyed and that the bone again becomes firm and hard upon the physiological activity of the periosteum and the bone cells in growing animals and in man. Von Hanseman also made a careful study of the dura mater, and he reports that it is not affected like the periosteum in rickets. If, by chance the rachitic process of the skull is complicated by a pathological process, he noted that the dura mater and the diploe are affected.

A further study of the internal surface of the rachitic skulls showed that there was no rachitic softening of the dural side, but that a softening of the bone occurs from the periosteal side and that the process of softening progresses from the outside inward toward the dura. It was also shown that when there is a complete softening of the bone present, it in no instance began on the dural side, but that it is an extension inward from the process on the periosteal side. In the young skulls the bone is very porous, while in the skulls of older animals it is a sclerotic process. In many of the skulls examined, the process greatly resembles that of a hyperostosis of the inner plates. One can thus readily understand why, in the beginning of the study of the disease, the outgrowth of the bone observed by the early investigators received such namesas osteosclerosis, hyperostosis, leontiasis, etc. In the deeper portions of the outbuilt bone are areas which are markedly softened. On maceration 
of skulls from rachitic monkeys, some greatly resemble a wasp's nest, while others resemble a sponge in structure. Von Hanseman, in his studies, macerated the skull of a ceropithicus in water at 37 degrecs centigrade for twenty-four hours, and at the end of that time he noted that the greater part of the upper jaw was lost, and that the portion which remained was composed of a few spongy bone nests. The weight of the skull in a dried state after this treatment was greatly reduced in comparison to the weight before being macerated. Another specimen examined, a papio porcarius, showed by measurement that the bone plates had a thickness of $1.8 \mathrm{~cm}$., and the skull weighed 102.2 grams, while another skull studied hy Von Hanseman, a papio hamadriasis, weighed 322.2 grams, and the thickness of the bone plates of the skull were $1.5 \mathrm{~cm}$. From the foregoing we learn that the bone plates of the first skull were $0.33 \mathrm{~cm}$. thicker than those of the second, but that the skull of the second was much heavier than the first. This difference in the weight of the two skulls is, no doubt, due to the increase of inorganic material in the second skull. If the animal with rickets does not die, the porous areas of the affected skull are soon filled with osseous material, as a result of which they become very heavy. Many times small areas are observed in which this process has not been completed, but if the animal had lived these areas would have been filled with the osseous material the same as the other areas which had been filled. In making a cut through bone affecterl with rickets, one notes that there are present areas which appear to be diploe. Microscopically the cut section of the bone of many skulls examined by Von Hanseman greatly resembles osteosclerosis. Von Hanseman, like Virchow, believes that it is a secondary process of hardening. Microscopically, one observes that there is not a normal lamellar system, but instead, there are concentric lamellar systems developed around the blood vessels. In this respect the disease in the monkeys resembles the pathological picture presented in man.

In other skulls studied of the papio olivaceus, papio hamadriasis, and lagothrix cana, there was a marked process of osteophytic building going on. Thus, from the foregoing, we learn that there is present an increase of the periosteum and also hyperostosis. This process was quite markedly persistent in the skull of a sclerotic hamadriasis. The marked thickening and sclerosis observed does not resemble a synostosis of the bones, and the binding together or holding together of the bones is not a locked union as is observed in normal sutures; but instead there is a partial union at one point and a complete union at another, or at no point can one discern a suture of the bones. In another specimen the bones of a rachitic skull showed a practically normal process of union. Thus one finds that even though rickets is and has been present, one will occasionally find that the disease is not constant in its markings. In other specimens examined, no union whatsoever was present, and the sutures were open. Many times the fontanels do not remain open, but closed, and here we again learn that this is not a positive symptom of the disease in monkeys. This last point, however, is a very valuable one for differentiation between monkeys and man; for in man, when rickets is present, the fontanels are always open in the young. The general picture presented in the rachitic skull is that it resembles a hyperostosis and a thickening which resembles a sclerosis. Because of the mixed 
appearances of the affected bone, one cannot classify the disease as either one or the other of the foregoing conditions, nor can one classify it as an exostosis. The softening of the bones is not an exostosis, for the reason that there is an actual softening of the bones first which is accompanied by an actual process of the building of the bone rather than a process of exostosis. This is an important point to be remembered between these two processes.

Bisher does not agree with the theory of Virchow that a hyperostosis and exostosis actually exist, but that the condition observed is an osteodevelopment which occurs after rickets. Von Hanseman does not agree with either of the above authors, but believes that rickets is conducive to an exostosis; and further he believes that an exostosis can develop in man and monkeys in the absence of rickets. Von Hanseman, on further study, observed the skull of a three-year-old ursus verginianus with a marked hyperostosis which increased to such an extent that the animal was blinded by the com. pression of the optic nerves as the result of the increased growth of bone. An examination of the eyes showed them to be normal. The nasal passages of this animal were closed by the excessive growth of the nasal septum, and a marked thickening of the upper jaw was noted that was osseous in character. This process was very pronounced between the lateral halves of the bones. The bone overlying the two central incisors was greatly increased in amount, and was composed of soft spongy osseous material. The great increase in the size of this animal's head gave it the appearance of a monster. Sutton, in further studies on rachitic skulls, learned that the foramen is variably diminished in size. Another specimen, examined by Von Hanseman, showed a very excessive overgrowth of the upper jaw, so that the nose or snout of the animal lost its normal contour and no longer resembled the physiognomy of a monkey, but that of a man. The most pronounced instances of this deformity were noted in two apes, the one a lagothrix cana and the other a papio porcarius. An examination of these heads showed that there was an overgrowth of the periosteum, but that the dura was not affected. This observation coincides with the observations made of the heads of humans affected with rickets. On further examination it was learned that there was no thickening of the bone plates of the head on the dural side, but that thickening developed from the periosteal side.

A study of the mandibles of some of the monkeys which were affected with rickets showed a thickening of the inner and outer plates. This thickening, however, was not uniform, for some parts showed a greater thickening than others. When the rami are affected by rickets, the thickening is not as marked as is the body of the mandible. In some of the specimens, the thickening of the body was so marked that the genial tubercles were partly obliterated. The angle of the jaw is rounded and compressed, while the margin of the mandible was thickened and round. The mandible is not a compact mass of bone, but is composed of soft spongy bone which is easily bent. One can not foretell how extensive the rachilic process really is in the human, but reasoning from analogy it is safe to assume that it is likewise affected. The influence of this disease, no doubt, is marked on the position of the deciduous teeth, for as the bone is soft and spongy and increased in size, the position of the deciduous teeth is without a doubt affected. If the animal has not erupted all of its deciduous teeth, one can, with a degree 
of certainty, predict that they are not likely to erupt, and if they do, they will in all likelihood be greatly deformed because of the nutritional disturbances which accompany rickets. Von Hanseman states, from his studies on the jaws of a cercocebus collaris, that the erupted teeth of these jaws showed no developmental changes, but that the unerupted teeth, after their eruption, fall an easy prey to caries; this can be explained by the fact that the teeth which erupt after the development of the disease are deficient in the compactness of the enamel and also in the inorganic substances which enter into its composition. Having learned that these marked changes are present in deciduous teeth in the process of development after rickets is developed, it is only rational to suppose that we can thus account for the many poorly developed permanent teeth, and many times the absence of permanent teeth. By the increase in the size of the maxillae and mandibles, brought about by rickets, the deciduous teeth are placed in many different positions, and further, as we well know, the roots of the deciduous teeth act as guides for the developing permanent teeth, therefore it is easy to understand that if these teeth are not in a normal relation that the permanent tecth likewise will not be. The alveolus in which the teeth are supported being a soft spongy mass is another factor of importance, when we consider the malposition of the teeth. And further, in lieu of the irregularity of the teeth, either deciduous or permanent, and the soft spongy alveolus; when they are brought into occlusion the bony support is not sufficient to maintain the position of the teeth, and they are forced into malocclusion, and if any of the teeth are rotated or tipped at one angle or another, this will, when brought into occlusion, cause a springing of the weak bony support, which in time gives away and the tooth takes on a greater angle and malocclusion goes from bad to worse. This process may be confined to a few or all of the teeth, and by this process the normal function of the teeth, namely the incisors for cutting, the canines for tearing, and the molars for grinding, is likewise impaired. In addition to the inconvenience of the malocclusion of the teeth, the animal can not masticate its food as it should, because of their insecureness; and further, when masticating its food, the teeth are very painful when brought into occlusion. Because of these many difficulties the animal refuses food, which at this time is indeed very necessary for its bodily needs in addition to the salts which the food contains and can be added thereto, which will supply it with the salts needed for the repair and the building of its osseous development.

Rickets is not a disease common to wild monkeys in their native state, but it is one which they soon contract when placed in captivity. At once we ask the question; what is the cause responsible for the development of the disease in these animals? Is it that these animals, in their wild state, live on certain foods rich in bone building salts, or is it necessary that they have a large range over which to roam? And further, is freedom and plenty of fresh air necessary to the health of the monkey? Is the air, the confinement, and small range of action which they are allowed in captivity responsible for rickets, or is the food which they receive deficient in the necessary salts for their osseous development; or are their hygienic surroundings in . captivity the cause of rickets? No doubt improper food, bad air, lack of sunshine, and limited range of action are all factors which are at the bottom 
of the trouble. Once the vitality of the animal is lowered, it is more of less susceptible to the development of rickets, and after the rickets is once developed, the vital forces of the animal are lowered to a greater degree than before, and the animal is more likely to contract tuberculosis; and further, the animal will, with very little exposure, contract pneumonia. These two diseases are the most common complications which monkeys can contract when afflicted with rickets.

Let us now summarize the findings learned by the study of rickets from the skulls of monkeys.

1. That the thickening of the skull is primarily confined between the periosteum and the bone, and that the thickening is never from the inside out. That process seldom, if ever, reaches the point which resembles craniostosis.

2. The skulls of young monkeys show a marked thickening in the fresh state, and on cut section show a marked thickening, and the cut surface is of a rich blood-red color. This latter fact shows that the bones are very highly vascularized, and on maceration they are shown to be very porous.

3. An examination of the skulls of older monkeys shows that the thickening noted is sclerotic in type, and that the spongyness observed in the skulls of the younger animals is absent.

4. It is learned that if the skulls of the younger animals are macerated they fall to pieces.

5. Skulls which present the appearance of an exostosis are not from animals suffering from rickets and therefore should not be classified as such.

Having described the onset, the invasion, and the course of development of the deformities and complications of rickets, let us now study some photographs which show very excellently the presence of the disease in the skulls of monkeys.

The following pictures were selected from Von Hanseman's "Rachitis des Schädels."

\section{Fig. 1-Papio Cynocephalus Leukopheus.}

An examination of the anterior portion of the superior maxillae shows an area of marked porosity of the bones which stands out in bold contrast to the area not affected. At the upper portion of the diseased area, we note that there are present many foramina in the substance of the porous bone. It is very queer indeed that the area lying between the canines should be the only area attacked by the disease. On the left side, one notes that there is a marked bulging over the root of the central incisor at its upper portion.

\section{Fig 2.-Papio Olivaceus.}

An examination of this picture of the skull shows at a glance the extent of the rachitic process. The line of union between the two halves of the maxillae are widely separated, and the nasal septum is gone. The line of union between the premaxilla and the maxilla proper stands out in bold contrast on the left side. On further examination, we observe that there is a marked thickening of the maxilla and also of the mandible, and in addition to this thickening the bones are very porous. A marked absorption of the 
bone covering the central and lateral incisors in the upper and the lower jaws is noted. On further examination we observe that crowns of the left supcrior central and lateral incisors are very poorly formed. On the labial surface of the right central incisor on its mesial half, one notes an area of

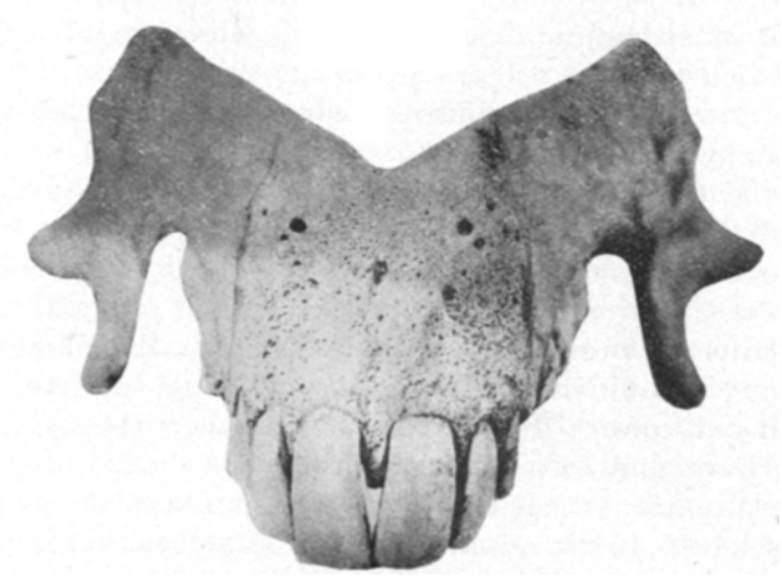

Fig. 1.

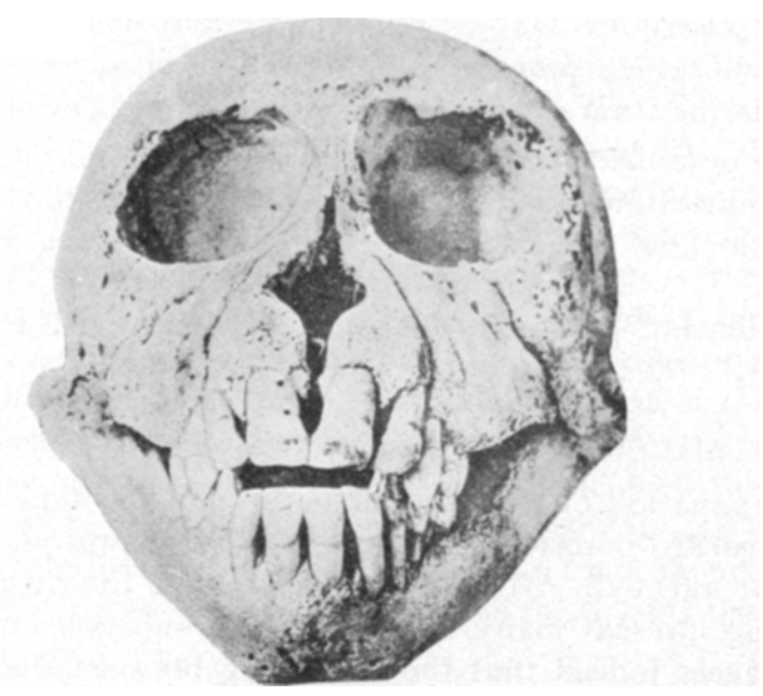

Fig. 2.

poorly developed tooth structure. Taking the skull of this animal as a whole one observes at a glance that the bones of the face are more markedly affected than any of the other bones.

\section{Fig. 3-Lower jaw of same animal.}

An examination of the lower jaw skull shows that it is greatly increased in thickness, and that the anterior portion shows a distinct porosity of its substance. The margins of the jaw are rounded, and the genial tubercles are obliterated. 


\section{Fig. 4-Macacus Nemistrimus.}

The picture of the skull of this animal shows very excellently what a very destructive process rickets is when it reaches its maximum. The lateral incisors on either side are lost, and the central incisors are in good approximation, yet there is no union between the two halves of the alveolus. The teeth, it will be noted, are tilted at many different angles, and the only teeth

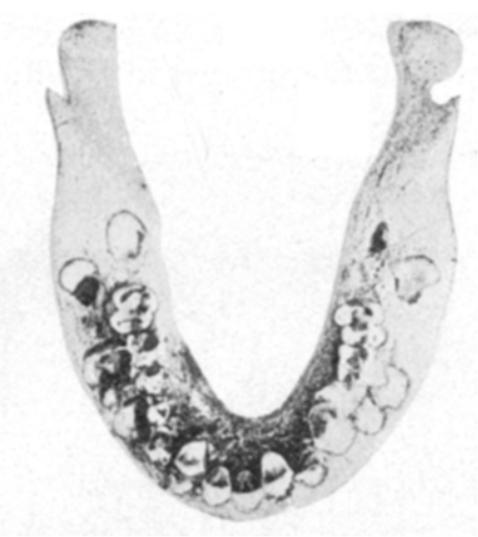

Fig. 3.

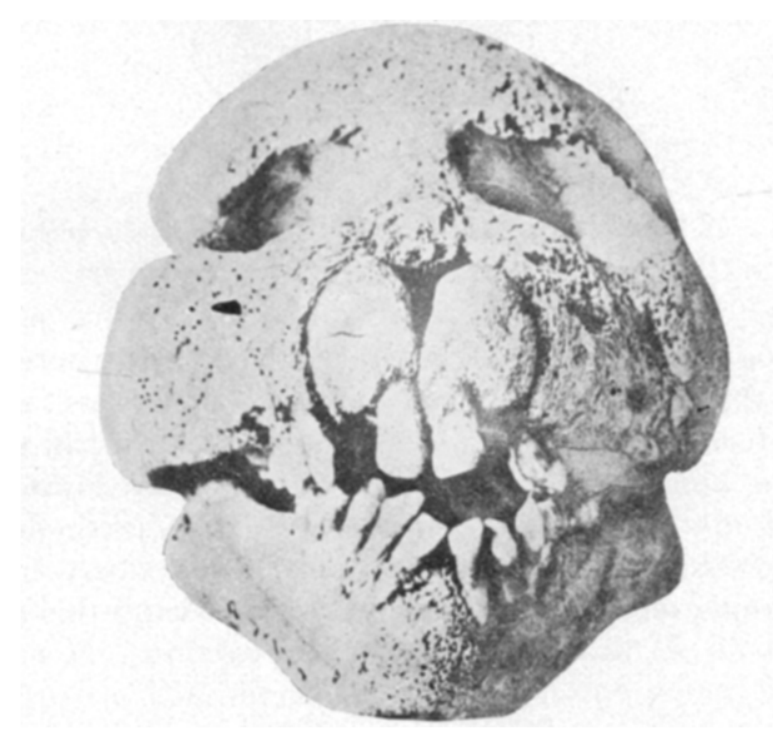

Fig. 4.

in occlusion are the molars. The teeth in the lower jaw all tip toward the mesial, and a variable amount of destruction of the alveolus around them is noted. The entire skull of this animal presents a marked porosity of the bones, a variable thickness of which is noted. The margins of the lower jaws are rounded, and it is greatly increased in all of its dimensions.

Fig. 5-Papio Porcarius.

This is the mandible of a papio porcarius, which was described by $\mathbf{B}$. Sutton in his work on rickets. This specimen presents a very interesting. 
study in that it shows a very marked thickening of the mandible in mass, and further shows the teeth are not in any definite position, some of them being in approximate contact, while others are out of their normal alignment. The genial tubercles are not visible and the thickening in this region is very marked. Note also the upper surface of the mandible, which is supporting the teeth; it is not inclined as in the normal, but offers a broad base.

One should carefully examine these pictures and form a mental impression of them, so that when confronted with a case of typical rickets one is fitted to compare, by analogy, the process in the human. Fortunately for

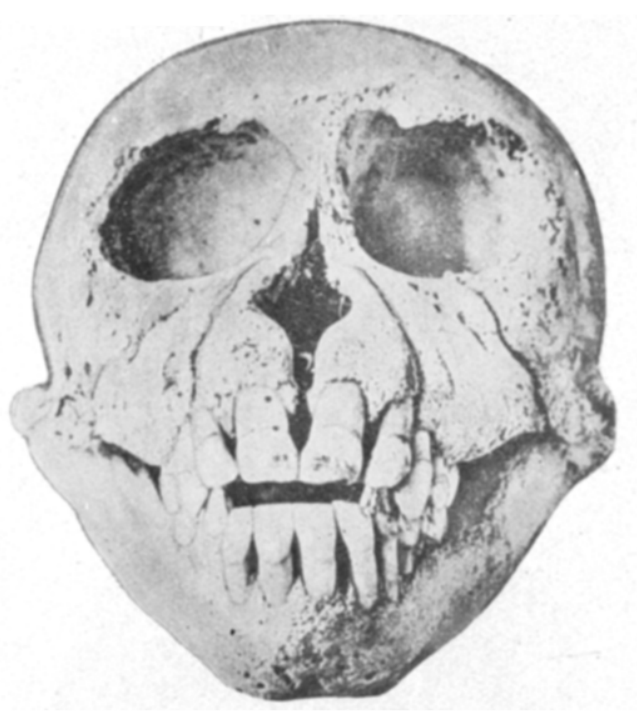

Fig. 5.

man, the disease is never allowed to progress to the extent noted in the apes, but it is possible that many times when the process is not as far advanced as shown by the pictures, it has advanced far enough in the child to bring about a condition of the bone which will be a very important factor etiologically responsible for many of the malocclusions noted by orthodontists. This latter statement is the reason for the appearance of this paper which the author hopes will be of some service to those who are practicing this specialty.

\section{BIBLIOGRAPHY.}

1. Ephem: Nat. Cur. Ann. 2. 1671 Obs. v., p. 6.

2. Citirt: Nach Bland Sutton, No. 15 .

3. Otto: Handbuch der path. Anat. des Menschen und der Tiere, Breslau, 1814.

4. Gurlt: Katalog des zoologischen Museums der Tierarztneischule zu Berlin, 1834, Magazin der ges. Tierheilkunde, 4 Jahrgang.

5. Citirt: Nach Bland Sutton, No. 15 .

6. Percey: Proceedings of the Pathological Society of London, Part XII, 1844.

7. Vrolik: Specimen anat. path. inaugurale de hyperostose cranii, Amsterdam, 1848.

8. Huschke: Ueber Craniosclerosis totalis rhitica, Jena, 1858.

9. Schmidt: Oesterr. Vierteljahrsschrift fuer wiss. Veterinarkunde, XX, I Heft.

10. Schmidt: Zool: K inik I, Krankheiten der Affen, Berlin, 1870.

1. Sutton: I eontasis osssea Ebenda, 1889.

12. Hutchinson, J: On osteitis deformens, The Illustrated Med. News, 1889

13. Rickets in Monkeys, Lions, Bears, and Birds. Journal of Comp. Med. and Surg., Vol. X., No. 1, 1889.

14. Gervais: Journal de Zool., 4 Bd., 1875. 
15. Hanseman: $Z$ wei Faelle von Mikrocephalie mit Rachitis. Bibloth. medicac.,Heft II.

16. Elsaesser: Der weiche Hinterkopf, 1883.

17. Virchow: Onkologie, Bd. 2.

18. Pommer: Osteomalacia und Rachitis, 1885

19. Hanseman: Zellstudien, 1893.

20. Virchow: Das Normale Knochenwachsthum und die Rachitischen Stoerungen desselben. Sein Arch., Bd. V., 1853.

21. Senator: Rachitis in v. Ziemessens Handbuch, Bd. 13, Heft. 1875.

22. Rehn: Rachitis in Gerhardt's Handbuch Kinderkrankheiten., Bd. 3. 1878.

23. Jadelot: Description anat d'une tet humain extraordinair, 1799.

24. Weber: Die Exostosen und Enchondrome, 1856.

25. Buhl: Hyperostose der Gesichts und Schaedelknochen. Mittheil. aus dem path. Institut, Muenchen, 1878.

\section{THE HISTORY OF ORTHODONTIA. \\ (Continued from page 571)}

BY BERNHARD WOLF WEINBERGER, D.D.S.

NEW YORK CITY.

CLAUDIUS Galenus or Galen.-Whatever progress was made in dental art seems to have been lost after the fall of the Roman Empire, as the only writer of later times who devoted much attention and time to the teeth and their diseases was Galen. After Hippocrates, Galen the founder of experimental medicine, was undoubtedly the ablest and perhaps the most renowned physician of his age. Born at Pergamos, a city in Asia Minor, in the year 131 of the present era, he died in 201. Lived most of his life in Rome, intimate with the emperors Lucius Verus, Marcus Aurelius, Commodus and Septimius Servus; was an extraordinarily voluminous writer on medicine and philosophy; lectured publicly on anatomy, practicing as a physician: At the age of seventeen, he began the study of medicine, but his activity as a student did not really begin until after the death of his father in 150 A.D., under the guidance of physicians of repute of his own country. He began to travel in foreign lands, in order to profit by the teachings of the most eminent men in his profession. "He studied under the rival sectarians of Dogmatists, Empirics, Methodists, Pneumatists and Eclectics, in the school of Alexandria. At the time of his appearance the schools of medicine were a prey to the most pernicious dissentions, the partisians of the school of Erasistratus, of Ilippocrates and of the Empirical, Methodical, and Electic sects, divided in their opinions, agreed but in one point, that of converting medicine into a tissue of frivolous subtleties and useless discussions. It the midst of this disorder Galen appeared, and returned to the safer road of patient thinking and accurate observation, which so much distinguished the Hippocratic School."

He devoted himself to the investigation of organic nature, and diligently pursued inquiries relative to the structure of animal bodies.

For thirteen centuries his system reigned supreme in Europe, Asia, and Africa. like Hippocrates, he was greatly in advance of his time, regarding anatomy as the hasis of medicine. Practically all his knowledge was gained from the dissection of lower animals. "The great duty of the physician he 